\title{
Study of Dielectric Properties and Morphology of Epoxy Resin with Silicon Dioxide Microparticles and Nanoparticles.
}

\author{
J. Hudec ${ }^{1}$, V. Neděla ${ }^{1}$ \\ 1. Environmental Electron Microscopy Group, Institute of Scientific Instruments of the CAS, Brno, \\ Czech Republic
}

It was found that better electrical properties of epoxy resin are achieved by adding of nanoparticles of silicon dioxide $\left(\mathrm{SiO}_{2}\right)$ [1]. It is assumed that homogeneous distribution of particles significantly improves these electrical properties. This paper deals with the study of impact of different percentage filling of microparticles and nanoparticles on the electrical properties of epoxy resin, with their comparison and with the study of the particles microstructure and distribution by environmental scanning electron microscope.

The sample consists of a mixture containing an epoxy resin CY228, hardener HY918, softener DY045, accelerator DY062 and microparticles and nanoparticles of silicon dioxide from Sigma Aldrich as a filler. This mixture is evacuated, subjected to ultrasound and then stiffened. It is expected that microparticles and nanoparticles should be equally distributed in whole volume of epoxy resin due to the influence of microwaves. There were made samples with $0.5,1$, and $2 \%$ (w/w) of particles for the experiment and values of the dissipation factor $\operatorname{tg} \delta$, permittivity $\varepsilon_{\mathrm{r}}$ and resistivity $\rho_{\mathrm{v}}$ were determined by measuring. For the characterization of the sample morphology the environmental scanning electron microscope (ESEM) QUANTA 650 FEG was used. Some samples were covered with a thin carbon layer to eliminate charging and they were observed in vacuum mode (beam energy $10 \mathrm{keV}$, probe current 50 pA, GSED detector). Spattered free samples were observed in the environmental mode of this microscope [2], [3] (beam energy $10 \mathrm{keV}$, probe current $50 \mathrm{pA}$, GSED detector, the water vapour pressure of $200 \mathrm{~Pa}$ ).

Our results indicate that the electrical properties of the samples with $1 \%(\mathrm{w} / \mathrm{w})$ of microparticles are essentially the same as for the samples with $1 \%(\mathrm{w} / \mathrm{w})$ of nanoparticles, but the electrical properties of the samples with $0.5 \%(\mathrm{w} / \mathrm{w})$ of microparticles are almost equivalent to the samples with $2 \%$ (w/w) of nanoparticles. Thus, the same properties can be achieved with the lower quantity of added particles and hence with the lower price. Regarding the above mentioned results, the samples with the better electrical properties are prepared, see Fig. 1. Unfortunately, despite the advanced procedure of the samples production, microparticles and nanoparticles are distributed nonhomogeneously in the epoxy resin. It is demonstrated by the formation of clusters, see Fig. 2 - 5. Microstructure of the epoxy resin with $2 \%(\mathrm{w} / \mathrm{w})$ of $\mathrm{SiO}_{2}$ nanoparticles coated with carbon layer can be seen in Figure 2. Spattered free samples are shown in Figures $3-5$. Figure 3 demostrates the cluster of nanoparticles as well as the cluster of microparticles is shown in Figure 4. Our ESEM results show possibility to observe the sample morphology and the particle details with the higher resolution than in conventional SEM as well as the true shape of particles in the volume of sample (see Fig. 5). This work was supported by the project [4].

\section{References:}

[1] Hudec J, et al., Fine Mechanics and Optics 60 (9) (2015), p. 268.

[2] Neděla V, et al., Nucl. Instrum. Methods in Physics A, 645 (1) (2011), p. 79.

[3] Maxa J, et al., Advances in Military Technology 7 (2) (2012), p. 39.

[4] The European Commission (ALISI No. CZ.1.05/2.1.00/01.0017) 

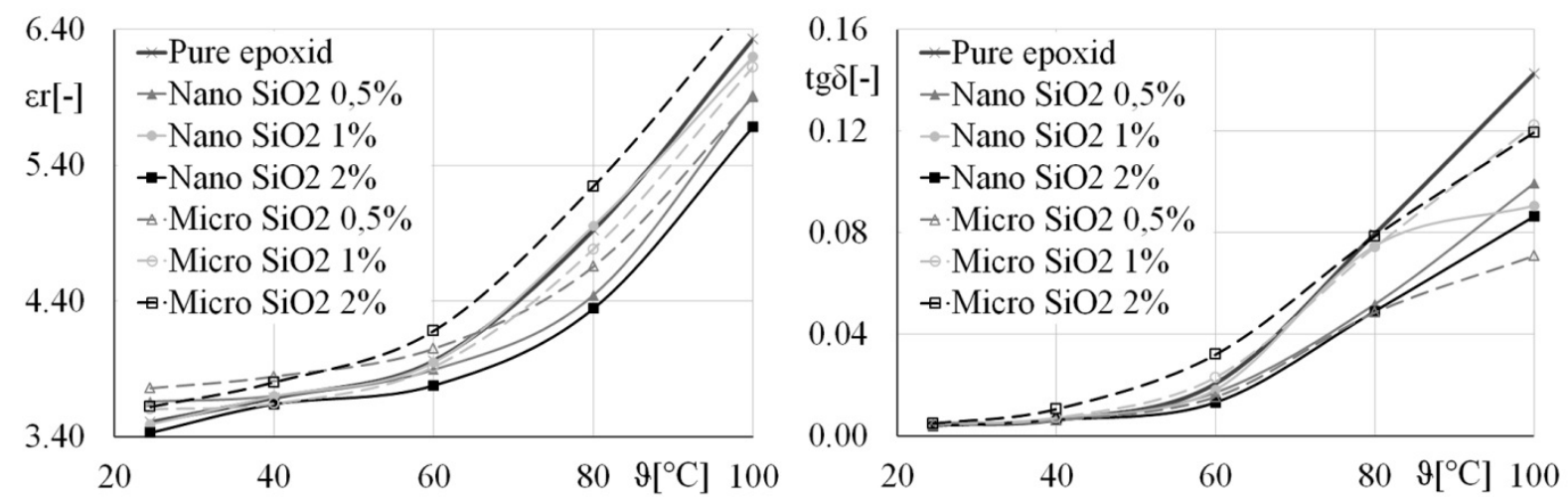

Figure 1. The comparison of the temperature dependences of dissipation factor and permittivity of pure epoxy and specimens with different percentage filling of micro and nanoparticles of silicon dioxide.

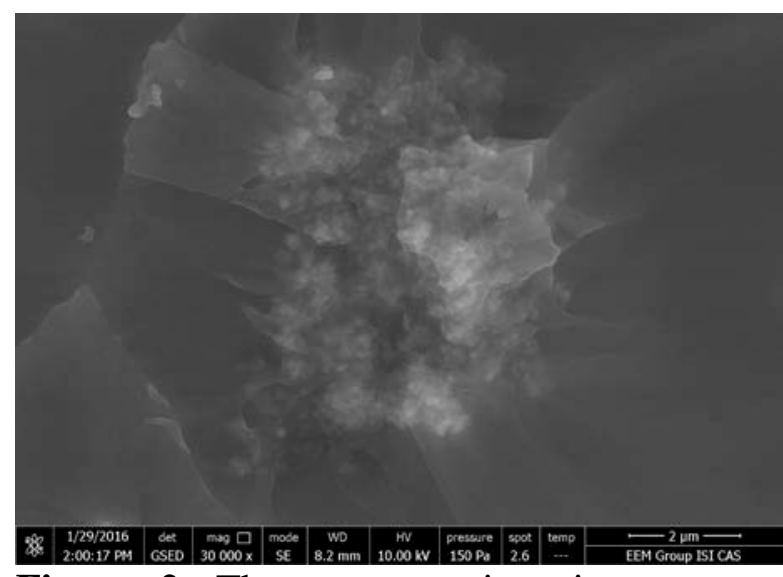

Figure 2. The epoxy resin microstructure with $2 \%(w / w)$ of $\mathrm{SiO}_{2}$ nanoparticles coated with carbon layer, beam energy $10 \mathrm{keV}$, probe current 50 pA, QUANTA 650 FEG

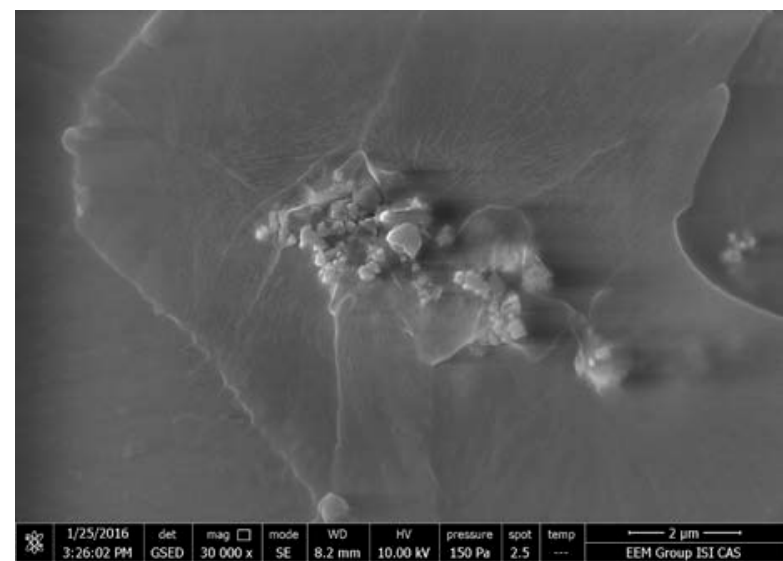

Figure 4. The spattered free epoxy resin microstructure with $2 \%(\mathrm{w} / \mathrm{w})$ of $\mathrm{SiO}_{2}$ microparticles, beam energy $10 \mathrm{keV}$, probe current 50 pA, QUANTA 650 FEG

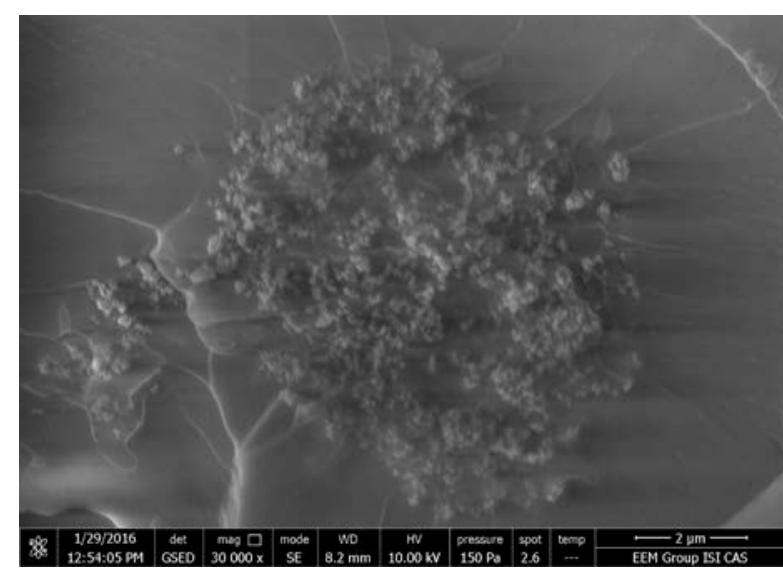

Figure 3. The spattered free epoxy resin microstructure with $2 \%(\mathrm{w} / \mathrm{w})$ of $\mathrm{SiO}_{2}$ nanoparticles, beam energy $10 \mathrm{keV}$, probe current 50 pA, QUANTA 650 FEG

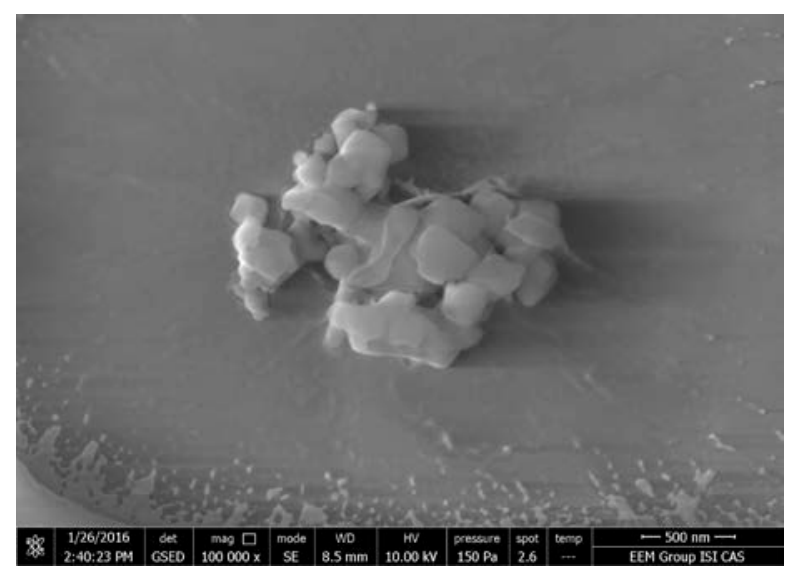

Figure 5. The high resolution image of the spattered free epoxy resin microstructure with $2 \%(\mathrm{w} / \mathrm{w})$ of $\mathrm{SiO}_{2}$ microparticles, beam energy $10 \mathrm{keV}$, probe current $50 \mathrm{pA}$, QUANTA 650 FEG 